\begin{tabular}{lcr}
\hline \multicolumn{3}{c}{ ANNALES } \\
UNIVERSITATIS MARIAE CURIE-SKŁODOWSKA & \\
& LUBLIN - POLONIA & \\
VOL. LXXI, 1 & SECTIO AA & 2016 \\
\hline
\end{tabular}

\title{
Lignosulfonate as a byproduct of wood pulp production: A potential precursor for the preparation of functional hybrid materials
}

\author{
Łukasz Klapiszewski, Tadeusz J. Szalaty, Tomasz Szatkowski \\ and Teofil Jesionowski \\ Institute of Chemical Technology and Engineering, \\ Faculty of Chemical Technology, Poznan University of Technology, \\ Berdychowo 4, 60-965 Poznan, Poland \\ *e-mail: teofil.jesionowski@put.poznan.pl
}

\begin{abstract}
Functional hybrid materials based on magnesium lignosulfonate and silica were obtained and characterized. Magnesium lignosulfonate is a common waste product of the wood pulp industry, while silica is a well-known inorganic material with exceptional physicochemical properties. In this study, silicas with a spherical particle shape were synthesized using a sol-gel method and alternatively in a nonpolar medium. Silica was found to improve the thermal and electrokinetic properties of the final products. The resulting lignosulfonate/silica hybrid materials were analyzed with the use of advanced techniques and measuring methods: scanning electron microscopy, a laser diffraction method enabling particle size measurements, Fourier transform infrared spectroscopy, elemental analysis, thermogravimetry, electrophoretic light scattering, zeta potential measurements, low-temperature nitrogen sorption, and colorimetric analysis. The results enabled the hybrid materials to be characterized from the point of view of potential applications in various branches of industry (for example as polymer fillers, electroactive blends and biosorbents). We additionally indicate new methods for the utilization of waste products, a category to which lignosulfonate certainly belongs.
\end{abstract}


Keywords: lignosulfonate/silica hybrid materials, magnesium lignosulfonate, amorphous silica, development of natural products, physicochemical and structural properties.

\section{INTRODUCTION}

The combining of organic and inorganic materials to obtain novel and functional hybrids is a topic of growing importance. Many such materials are synthesized with the use of natural macromolecules such as cellulose [1-3], lignin [4-6] or lignosulfonate [7-8].

An inorganic product frequently used in the preparation of multifunctional hybrid materials is silica. Silicon dioxide possesses some extraordinary physicochemical, electrokinetic, thermal and other properties which make it useful in the field of synthesis of hybrid materials. Silica can be obtained via several methods, of which the most important are the sol-gel method [9-11], precipitation from an aqueous solution of sodium silicate in polar $[12,13]$ and nonpolar $[14,15]$ media, the pyrolysis method [16], and others. Various methods make it possible to synthesize silica products with defined physicochemical properties, suitable for different applications.

Lignosulfonates (LS) are natural polymers formed in the process of separation of lignin from cellulose fibers in the sulfide method or in the sulfate dissolution process, called the kraft process [17, 18]. LS have the highest molecular mass among technical lignins. They form particles with a high degree of crosslinking, and hence the structures formed by them are very complex. The properties of LS result from the presence of hydrophilic groups, including strongly acidic sulfonate and hydroxyl groups, as well as hydrophobic groups originating from the aromatic rings and aliphatic chains which form the basis of the lignin structure [19, 20]. Hydrophobic groups construct the core of the compound, forming spherical or ellipsoidal structures. Aromatic rings stabilize the structure of the macromolecule. Owing to the presence of both hydrophilic and hydrophobic groups, lignosulfonates have become an interesting subject of research. Lota and Milczarek [21] suggested the use of LS for the construction of capacitors. They improve the resistance of electrodes to the humidity of the environment. The results of their experiment showed that LS increased the capacitance of the device. LS can also be utilized in the production of electrochemical sensors or biosensors [21]. LS can be applied as an adhesive prepared based on phenol-formaldehyde resins. In 
relation to the utilization of phenol, which is toxic and whose price depends on fluctuations in the gas market, interest in the use of lignosulfonates is certainly justified [22]. LS are good dispersive agents, for example to disperse dyes or carbon black [20]. Moreover, they can be used as cleaning agents due to their surface active properties. When used as an ingredient in concrete, cement or gypsum, LS act as natural plasticizers or superplasticizers and improve the rheological properties of the mixtures. They can also be used as additives in other building materials such as bricks and gypsum cardboard plate, and limit the water content of the materials [23]. Use of LS in combination with fish gelatin improves the mechanical properties and mechanical performance of composite foil [7]. Due to their anti-oxidizing properties, LS are useful components of food packaging materials, offering low toxicity and resistance to water activity [7]. Lignosulfonates have also been applied as an additive to drilling fluid in order to improve the effectiveness of oil extraction. Due to their adsorptive and surface active properties these materials cause the agglomeration of dust particles, which then precipitate and can be easily collected. This reduces the quantity of dust formed and improves working conditions [24]. By means of the appropriate reactions, lignosulfonate can be transformed into vanillin - a substance used in the food and pharmaceutical industries and in cosmetics. Interest in the production of synthetic vanillin results from the unstable situation on the market for extraction of natural vanillin [25]. The surface active properties of LS have been used in materials serving as additives to pesticides used in plant protection. Much research has been devoted to investigation of the toxicity of surfactants on plants. Roszyk et al. [26] studied the impact of lignosulfonate as a surfactant agent in pesticides on tomato and cauliflower. The results of their experiment showed that the biopolymer does not cause phytotoxicity and that the plants tolerate the material even in large amounts.

We report here the results of an experiment in which magnesium lignosulfonate, a renewable biopolymer formed in the process of paper production, was interconnected with silica, an inorganic material with defined physicochemical and structural properties. By means of the interconnection process we obtained a new group of products with improved parameters, which can be applied in various fields of industry. The resulting magnesium lignosulfonate/silica hybrid materials were analyzed to determine key physicochemical, dispersive-morphological, electrochemical and other parameters. 


\section{EXPERIMENTAL}

\subsection{Materials used for the preparation of organic/inorganic products}

\subsubsection{Magnesium lignosulfonate}

Magnesium lignosulfonate (MLS) was used in the form of a dense liquid at 55\% concentration (VIANPLAST 55, BIOTECH Lignosulfonate Handels-GesmbH, Austria). VIANPLAST lignosulfonates are thickened sulfite waste liquors having the sugar content removed. Their basic component consists of magnesium salts of lignosulfonic acids, formed by the decomposition of the non-cellulose part of wood. They have a wide range of industrial applications, for example as a plastifying agent in mortar and concrete mixtures, and as a binder in ceramics manufacturing.

\subsubsection{Stöber silica}

Stöber silica (SS) was synthesized by a sol-gel method involving simultaneous hydrolysis and condensation of tetraethoxysilane TEOS (analytical grade; Sigma-Aldrich, Germany) in a medium of $95 \%$ ethyl alcohol (analytical grade; Chempur, Poland) and 25\% ammonia (analytical grade; Chempur, Poland).

A simplified diagram of the technological process of sol-gel silica preparation appears in Fig. 1. A detailed description of this method of silica synthesis is presented in earlier published work [11].
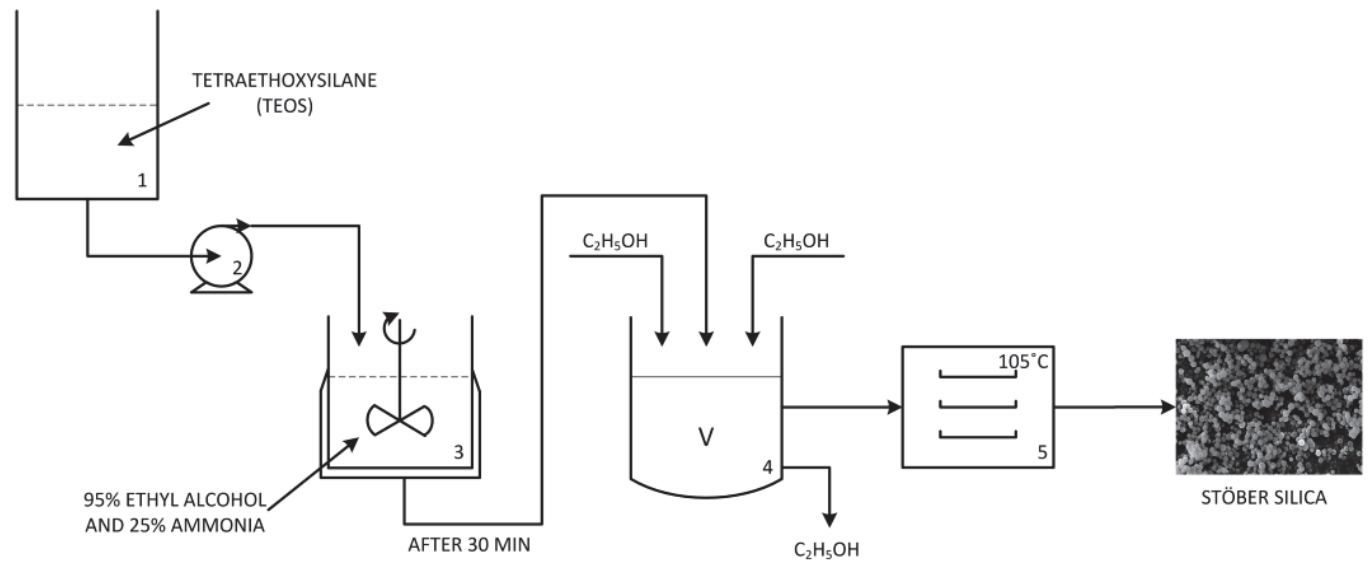

Fig. 1. Technological process for the production of silica by the sol-gel method ( 1 - container, 2 - pump, 3 - reactor, 4 - vacuum filter, 5 - convection dryer). 


\subsubsection{Emulsion silica}

Emulsion silica (ES) - precipitated in a nonpolar media - was obtained using sodium silicate as the precursor of $\mathrm{SiO}_{2}$, with hydrochloric acid as precipitating agent and cyclohexane as solvent. Figure 2 shows a simplified diagram of the technological process of silica synthesis in a non-polar media. A detailed description of this method of silica precipitation and characterization of its product appear in previously published papers $[6,15]$.

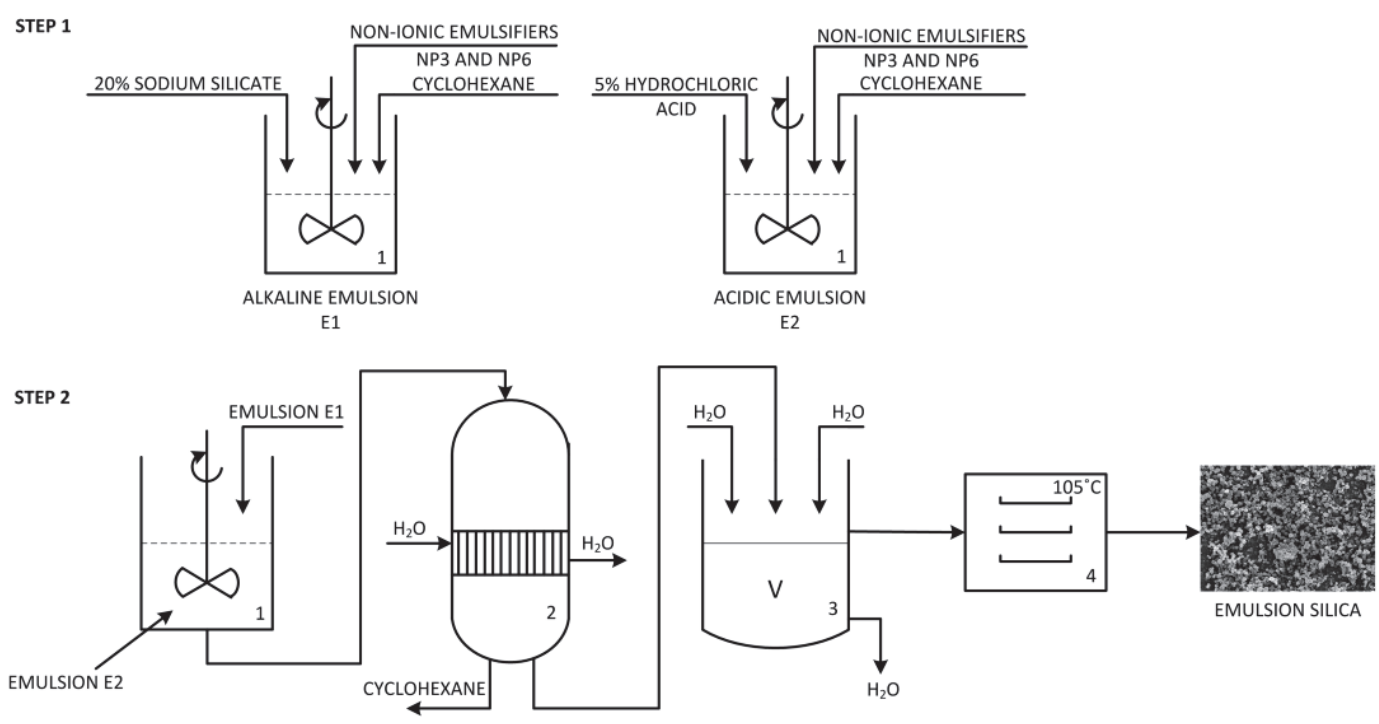

Fig. 2. Technological process for the production of silica in a nonpolar media (1 - mixing device, 2 - vacuum evaporator, 3 - vacuum filter, 4 - convection dryer).

\subsection{Preparation of hybrid materials from magnesium lignosulfonate and} silica precursors

To obtain magnesium lignosulfonate/silica hybrid materials (Fig. 3) an appropriate quantity of magnesium lignosulfonate was first placed in a reactor with $100 \mathrm{~cm}^{3}$ of distilled water. The aqueous solution of lignosulfonate derivative underwent constant stirring (1200 rpm) for about 30 min with the use of a high-speed mixer (Eurostar IKA-Werke $\mathrm{GmbH} \& \mathrm{Co}$. KG, Germany). In the next step, $5 \mathrm{~g}$ of inorganic support (Stöber silica or emulsion silica) dispersed in $100 \mathrm{~cm}^{3}$ of water was added to the lignosulfonate solution. The system was then homogenized for $2 \mathrm{~h}$. After this time the product (magnesium lignosulfonate/ $\mathrm{SiO}_{2}$ hybrid) was placed in a vacuum evaporator (Büchi Labortechnik AG, Switzerland) in 
order to evaporate the solvent. The final product was dried in a stationary dryer (Memmert, Germany) at $105^{\circ} \mathrm{C}$ for about $12 \mathrm{~h}$.

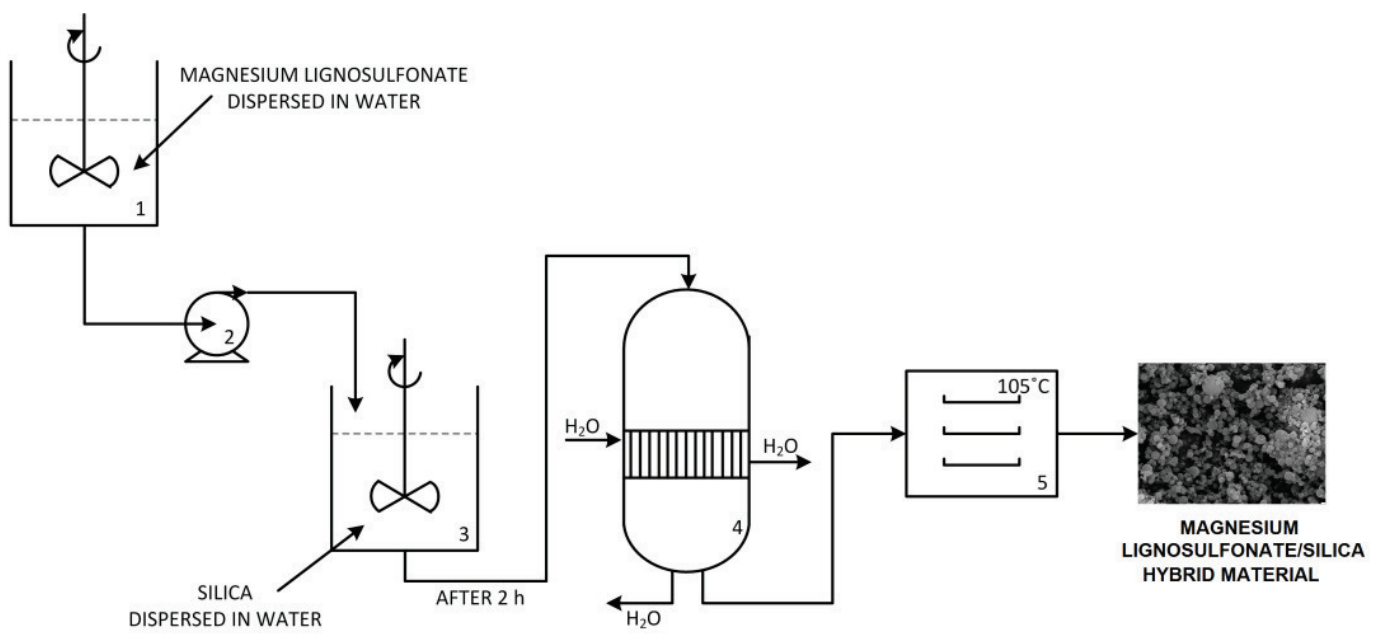

Fig. 3. Technological scheme of preparation of magnesium lignosulfonate/silica hybrid material - simplified technological process ( 1 - mixing device, 2 - pump, 3 - reactor, 4 - vacuum evaporator, 5 - convection dryer).

\subsection{Evaluation of physicochemical properties}

The particle size distribution of the hybrid materials was determined in the range 0.2-2000 $\mu \mathrm{m}$ using a Mastersizer 2000 (Malvern Instruments Ltd., UK) employing the laser diffraction scattering method, and their morphology was analyzed using scanning electron microscope (SEM) images taken on a Zeiss EVO40 microscope (Germany). Before testing, the samples were coated with $\mathrm{Au}$ for a time of $5 \mathrm{sec}$ using a Balzers PV205P coater.

The presence of the functional groups was investigated by means of Fourier transform infrared spectra (FTIR), recorded on a Vertex 70 spectrometer (Bruker, Germany). Here the materials were analyzed in the form of tablets, made by pressing a mixture of anhydrous $\mathrm{KBr}$ (ca. $0.1 \mathrm{~g}$ ) and $1 \mathrm{mg}$ of the tested substance in a special steel ring under a pressure of approximately $10 \mathrm{MPa}$.

Elemental contents of the products were established with the use of a Vario EL Cube instrument (Elementar Analysensysteme $\mathrm{GmbH}$, Germany), which is capable of registering the content of carbon, hydrogen, and sulfur in samples following high-temperature combustion.

The electrokinetic behavior of the materials was evaluated on the basis of zeta potential measurements made on a Zetasizer Nano ZS 
(Malvern Instruments Ltd., UK) using the electrophoretic light scattering technique (ELS). The measurements were performed in a $0.001 \mathrm{M}$ solution of $\mathrm{NaCl}$.

Porous structure properties of the hybrid materials were obtained by determination of the BET surface area, total pore volume and mean pore size calculated by the BJH method. Relevant measurements were made on an ASAP 2020 instrument (Micromeritics Instrument Co., USA).

A thermogravimetric (TG) analyzer (Jupiter STA 449F3, Netzsch, Germany) was used to investigate the thermal stability of the samples. Measurements were carried out under flowing nitrogen $\left(10 \mathrm{~cm}^{3} / \mathrm{min}\right)$ at a heating rate of $10{ }^{\circ} \mathrm{C} / \mathrm{min}$ over a temperature range of $25-1000^{\circ} \mathrm{C}$, with an initial sample weight of approximately $5 \mathrm{mg}$.

Colorimetric analyses of the samples were made using the CIE $L^{*} a^{*} b^{*}$ system and a Specbos 4000 spectrophotometer (Technische Instrumente $\mathrm{GmbH}$, Germany). The three coordinates of the CIE $L^{*} a^{*} b^{*}$ system represent the lightness of the color $\left(L^{*}=0\right.$ yields black and $L^{*}=100$ indicates diffuse white; specular white may be higher), its position between red/magenta and green $\left(a^{*}\right.$, negative values indicate green while positive values indicate magenta), and its position between yellow and blue $\left(b^{*}\right.$, negative values indicate blue and positive values indicate yellow).

\section{RESULTS AND DISCUSSION}

\subsection{SEM images and dispersive properties}

The particles of silica used in the experiment exhibited a relatively high uniformity and regular, spherical shape. The dispersive parameters given in Table 1 provide confirmation of this uniformity. It can be seen from the table that for the silica obtained via the sol-gel method, $10 \%$ of particles by volume have a diameter less than $5.7 \mu \mathrm{m}, 50 \%$ less than $12.1 \mu \mathrm{m}$, and $90 \%$ up to $22.6 \mu \mathrm{m}$. Similarly good parameters were noted for the silica obtained in nonpolar media. The SEM microphotographs (Fig. 4) also show the dispersive-morphological uniformity of the particles. Although the silicas used in the experiment did not demonstrate a significant tendency to agglomerate, in the case of the hybrid materials the tendency towards agglomeration was higher. The dispersive parameters of the analyzed hybrid materials indicate that the products tend to agglomerate more as the magnesium lignosulfonate content in the material increases (see Table 1). Similar results were obtained in earlier 
studies in which different kinds of silica and kraft lignin were used $[5,27]$.

Table 1. Dispersive properties of magnesium lignosulfonate/ $\mathrm{SiO}_{2}$ hybrid materials and the pure precursors used in their production.

\begin{tabular}{|c|c|c|c|c|c|}
\hline \multirow{2}{*}{$\begin{array}{c}\text { Type } \\
\text { of } \mathrm{SiO}_{2} \\
\text { synthesis }\end{array}$} & \multirow{2}{*}{$\begin{array}{l}\text { Content of MLS in } \\
\text { relation to the silica } \\
\text { matrix } \\
\text { (wt./wt.) }\end{array}$} & \multicolumn{4}{|c|}{ Dispersive properties } \\
\hline & & $\mathrm{d}(0.1)$ & $\mathrm{d}(0.5)$ & $\mathrm{d}(0.9)$ & $\mathrm{D}[4.3]$ \\
\hline \multirow{3}{*}{$\begin{array}{l}\text { sol-gel } \\
\text { method }\end{array}$} & 3 & 4.3 & 10.8 & 21.5 & 11.9 \\
\hline & 20 & 4.3 & 10.6 & 20.3 & 11.5 \\
\hline & 50 & 4.7 & 11.8 & 28.3 & 14.1 \\
\hline \multirow{3}{*}{$\begin{array}{c}\text { nonpolar } \\
\text { media }\end{array}$} & 3 & 4.0 & 16.8 & 38.7 & 19.0 \\
\hline & 20 & 4.3 & 25.6 & 45.3 & 26.3 \\
\hline & 50 & 5.4 & 28.3 & 49.7 & 27.7 \\
\hline \multicolumn{2}{|c|}{ Stöber silica (SS) - sol-gel method } & 5.7 & 12.1 & 22.6 & 13.3 \\
\hline \multicolumn{2}{|c|}{ Emulsion $\mathrm{SiO}_{2}(\mathrm{ES})$ - nonpolar media } & 4.1 & 17.3 & 39.5 & 19.9 \\
\hline \multicolumn{2}{|c|}{ Magnesium lignosulfonate (MLS) } & 8.7 & 45.3 & 85.9 & 49.7 \\
\hline
\end{tabular}
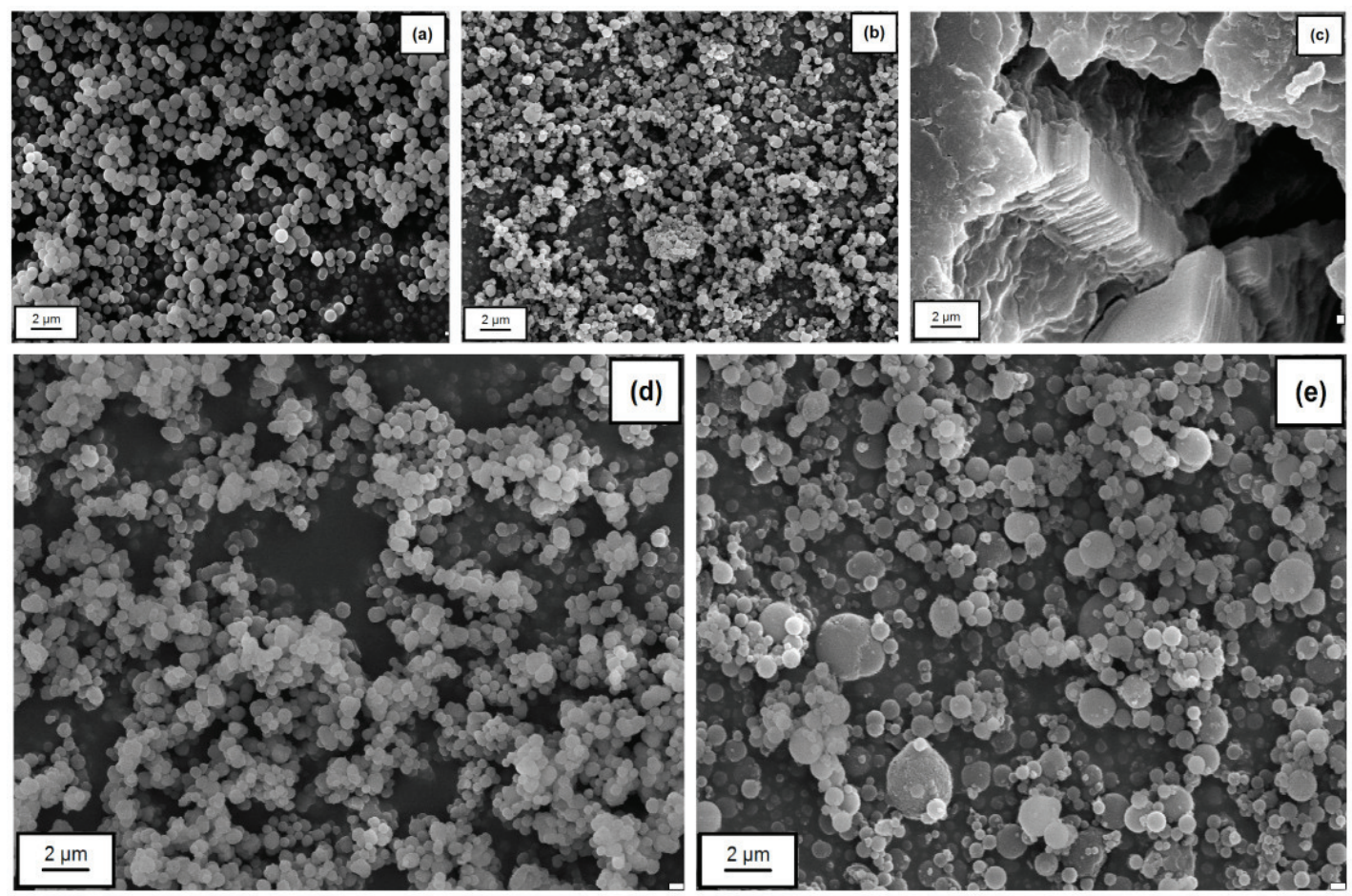

Fig. 4. SEM microphotographs of Stöber silica - SS (a), emulsion silica - ES (b), magnesium lignosulfonate - MLS (c), SS + 20 wt./wt. of MLS (d), and $\mathrm{ES}+20 \mathrm{wt} . / \mathrm{wt}$. of MLS (e). 


\subsection{FTIR spectroscopy evaluations}

The signals generated by specific functional groups in the supports and in the hybrid materials are presented in detail in Table 2.

Table 2. Vibrational wavenumbers $\left(\mathrm{cm}^{-1}\right)$ obtained from magnesium lignosulfonate (MLS), Stöber and emulsion silicas (SS and ES), MLS/SS and MLS/ES products.

\begin{tabular}{|c|c|c|c|c|}
\hline MLS & SS/ES & MLS/SS & MLS/ES & $\begin{array}{l}\text { Vibrational } \\
\text { assignment }\end{array}$ \\
\hline- & 3648 & 3648 & - & $\mathrm{Si}-\mathrm{OH}$ stretching \\
\hline 3420 & 3460 & 3450 & 3445 & O-H stretching \\
\hline 2937 & - & 2940 & 2943 & $\begin{array}{l}\mathrm{CH}_{3}+\mathrm{CH}_{2} \\
\text { stretching }\end{array}$ \\
\hline- & 1680 & 1680 & 1680 & $\begin{array}{l}\mathrm{H}_{2} \mathrm{O} \text { (physically } \\
\text { adsorbed water) }\end{array}$ \\
\hline $\begin{array}{l}1602 \\
1515 \\
1416\end{array}$ & - & $\begin{array}{l}1603 \\
1516 \\
1418\end{array}$ & $\begin{array}{l}1605 \\
1518 \\
1420\end{array}$ & $\begin{array}{c}\mathrm{C}-\mathrm{C}, \mathrm{C}=\mathrm{C} \\
\text { (aromatic } \\
\text { skeleton), } \\
\text { stretching }\end{array}$ \\
\hline 1158 & - & overshadowed & overshadowed & $\mathrm{C}-\mathrm{O}$ stretching \\
\hline 1124 & - & overshadowed & overshadowed & $\begin{array}{l}\mathrm{C}-\mathrm{O}-\mathrm{C} \text { (ring), } \\
\mathrm{C}-\mathrm{O} \text { stretching }\end{array}$ \\
\hline - & 1105 & 1105 & 1105 & $\mathrm{Si}-\mathrm{O}-\mathrm{Si}$ stretching \\
\hline 1044 & - & overshadowed & overshadowed & $\begin{array}{l}\mathrm{CH} \text { (aromatic) } \\
\text { stretching }\end{array}$ \\
\hline- & 989 & 991 & 993 & $\begin{array}{l}\mathrm{Si}-\mathrm{O} \text { assymetric } \\
\text { stretching }\end{array}$ \\
\hline- & 860 & 862 & 865 & $\begin{array}{l}\mathrm{Si}-\mathrm{O} \text { symetric } \\
\text { stretching }\end{array}$ \\
\hline 823 & - & overshadowed & overshadowed & $\begin{array}{c}\text { Aromatic } \mathrm{C}-\mathrm{H} \\
\text { (guaiacyl unit), } \\
\text { bending }\end{array}$ \\
\hline 769 & - & - & - & $\begin{array}{l}\mathrm{CH} \text { (aromatic) } \\
\text { bending }\end{array}$ \\
\hline 653 & - & 655 & 657 & $\mathrm{CH}_{\mathrm{x}}$ deformating \\
\hline 621 & - & 621 & 621 & $\begin{array}{l}\mathrm{SO}_{2} \mathrm{OH} \text { (sulfonic } \\
\text { groups), stretching }\end{array}$ \\
\hline 530 & - & 535 & 535 & $\mathrm{CH}_{\mathrm{x}}$ bending \\
\hline- & 469 & 472 & 475 & $\mathrm{Si}-\mathrm{O}$ bending \\
\hline
\end{tabular}



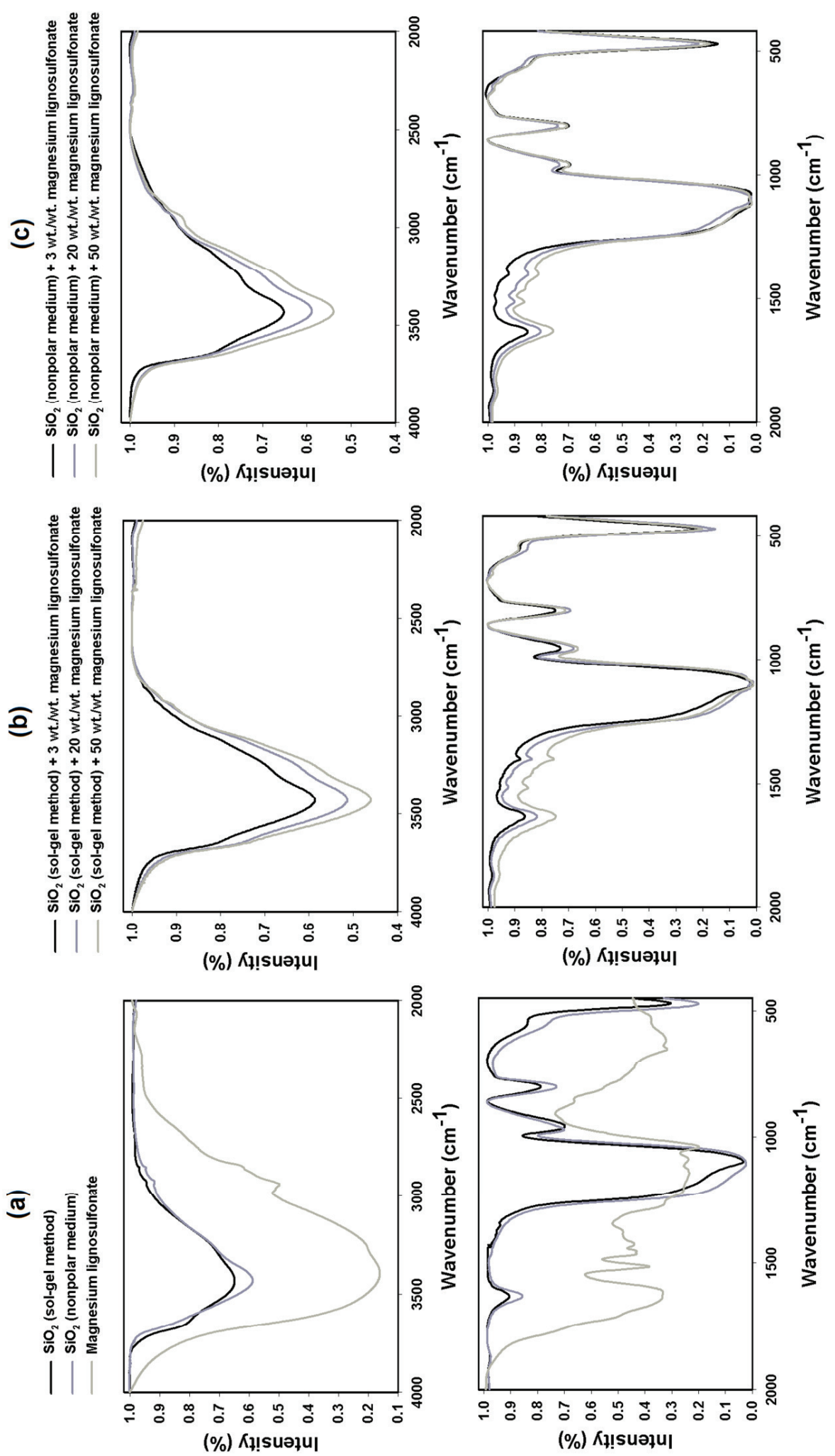

Fig. 5. FTIR spectra of precursors (a), and of silica/lignosulfonate hybrid materials based on Stöber (b) and emulsion (c) silicas. 
In the spectra of the hybrid materials based on silica synthesized via the sol-gel method (Fig 5a), characteristic bands of the support as well as of magnesium lignosulfonate are visible. Bands are found at wavenumbers 1602,1515 and $1416 \mathrm{~cm}^{-1}$ and originate from stretching vibrations of carbon-carbon bonds in the aromatic ring [28]. Other signals, characteristic of the lignosulfonate precursor, occur in the range $1158-1044 \mathrm{~cm}^{-1}$. However, these bands are covered by an intense band originating from silica with maximum at $1105 \mathrm{~cm}^{-1}$. Signals at 653 and $530 \mathrm{~cm}^{-1}$ are also visible; these originate from various vibrations of $\mathrm{CH}_{\mathrm{x}}$ groups contained in the magnesium lignosulfonate [29]. Additional confirmation of the effective synthesis route of the hybrid materials is provided by the band with maximum at wavenumber $621 \mathrm{~cm}^{-1}$, generated by the sulfonate group $\left(\mathrm{SO}_{2} \mathrm{OH}\right)-\mathrm{Fig}$. 5b [30]. It is noteworthy that with an increase in the weight contribution of magnesium lignosulfonate in the hybrid material, the peaks characteristic of that precursor intensify. This is particularly visible for bands originating from aromatic fragments and in the case of the signal generated by hydroxyl groups at $3450 \mathrm{~cm}^{-1}$. Also significant is the shift of the bands originating from lignosulfonate toward higher wavenumber values. This effect most likely results from the formation of hydrogen bonds between the silica support and magnesium lignosulfonate.

A similar situation is observed in the case of hybrid materials prepared with the use of a silica support synthesized in nonpolar media (Fig. 5c). Although the same signals are visible as in the case of sol-gel silica, their shift toward higher wavenumbers (relative to pure magnesium lignosulfonate) is greater, suggesting that a larger quantity of hydrogen bonds were formed. Also the intensity of the visible signals, in comparison with sol-gel silica, is greater. This observation indicates the higher content of lignosulfonate in the obtained material, additionally confirmed by the higher number of hydrogen bonds. The intensity also increases with increasing weight contribution of the lignosulfonate precursor in the hybrid materials.

\subsection{Elemental analysis}

The effectiveness of the synthesis of lignosulfonate/silica hybrid materials was confirmed by investigation of the content of elemental carbon, hydrogen and sulfur (see Table 3). The trace amounts of carbon and hydrogen in the analyzed silicas are certainly due to the presence of unreacted and/or unwashed reagents. The percentage content of elements in the magnesium lignosulfonate confirms its hydrophobic-hydrophilic 
properties, i.e. the presence of sulfur originating from sulfonate groups, and on the other hand the presence of carbon and hydrogen originating from the phenylpropane structure of lignin.

Elemental analysis of the magnesium lignosulfonate/silica hybrid materials confirmed the effectiveness of the proposed synthesis method. It is easily observable that with an increase in the lignosulfonate content in the hybrid materials, the recorded quantities of carbon, hydrogen and sulfur also increase. More effective interconnection of $\mathrm{SiO}_{2}$ with MLS was observed for emulsion silica (similar conclusions were drawn from the analysis of FTIR spectra and colorimetric data).

Table 3. Elemental content of carbon, hydrogen and sulfur in magnesium lignosulfonate/silica hybrid materials and in the precursors used.

\begin{tabular}{ccccc}
\hline \multirow{2}{*}{$\begin{array}{c}\text { Type } \\
\text { of } \begin{array}{c}\text { SiO } \\
\text { synthesis }\end{array}\end{array}$} & $\begin{array}{c}\text { Content of magnesium } \\
\text { lignosulfonate in relation to } \\
\text { the silica matrix } \\
\text { (wt./wt.) }\end{array}$ & \multicolumn{3}{c}{ Elemental content $(\%)$} \\
\cline { 3 - 5 } & 3 & $\mathrm{C}$ & $\mathrm{H}$ & $\mathrm{S}$ \\
\hline \multirow{2}{*}{ sol-gel } & 20 & 3.31 & 1.46 & 0.19 \\
method & 50 & 7.89 & 2.32 & 1.58 \\
\hline \multirow{2}{*}{ non-polar } & 3 & 3.03 & 1.96 & 0.25 \\
media & 20 & 5.97 & 2.32 & 0.73 \\
& 50 & 9.58 & 2.75 & 1.65 \\
\hline Stöber silica (sol-gel method) & - & 1.30 & - \\
Emulsion silica (non-polar media) & 2.62 & 1.89 & - \\
Magnesium lignosulfonate & 37.19 & 4.94 & 4.00 \\
\hline
\end{tabular}

\subsection{Electrokinetic stability evaluations}

Figure 6 shows the dependency of zeta potential on the $\mathrm{pH}$ of the prepared silicas, magnesium lignosulfonate and hybrid materials. Figures $6 \mathrm{a}$ and $6 \mathrm{~b}$ show results of the products based on Stöber silica and emulsion silica, respectively. The measurements were carried out over a wide range of $\mathrm{pH}$ values, from 1 to 11 .

Magnesium lignosulfonate is a derivative of lignin containing the additional sulfonate group $\mathrm{SO}_{3}{ }^{-}$. The electrokinetic potential of magnesium lignosulfonate, regardless of the $\mathrm{pH}$, is always negative and ranges from $-13 \mathrm{mV}$ at the lowest $\mathrm{pH}$ down to $-35 \mathrm{mV}$ at the highest $\mathrm{pH}$ [32]. This is caused by the presence of a number of hydroxyl, carboxylic 
and sulfonate groups in the structure of the biopolymer. These functional groups are of acidic character, and during dissolution generate a negative charge [33, 34].

(a)

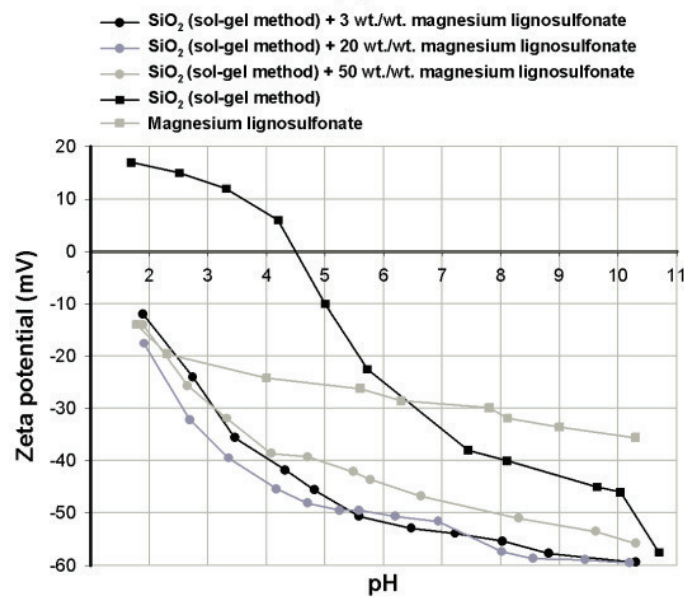

(b)

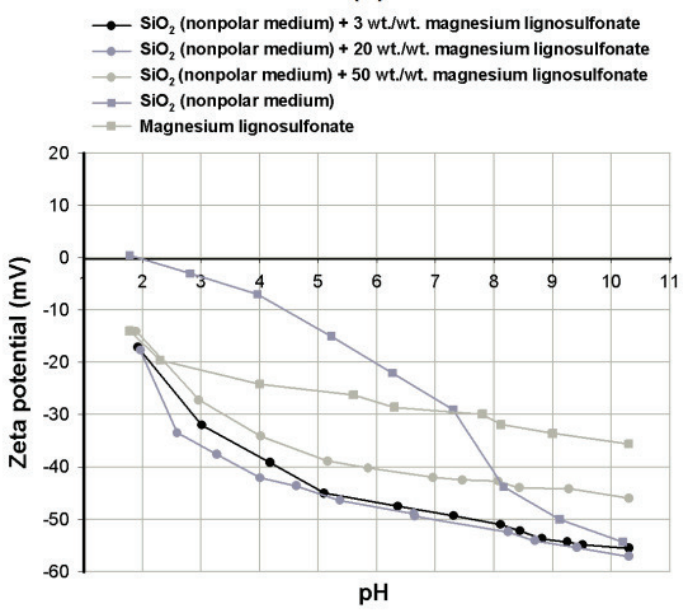

Fig. 6. Zeta potential vs. $\mathrm{pH}$ of magnesium lignosulfonate/ $/ \mathrm{SiO}_{2}$ hybrid materials based on Stöber silica (a) and emulsion silica (b).

The electrokinetic properties of silicon dioxide differ depending on the route of synthesis. The isoelectric point of emulsion silica (Fig. 6b) occurs at $\mathrm{pH}=1.7$, and the zeta potential has negative values. In the case of Stöber silica synthesized via the sol-gel method, IEP $=4.5$ (Fig. 6a). The electrokinetic potential is positive in acidic conditions, but decreases with increasing $\mathrm{pH}$, reaching a minimum value of $-52 \mathrm{mV}$. It was observed that the colloidal system of both emulsion and Stöber silica is stable in neutral and basic conditions (values of the zeta potential are clearly smaller than $-30 \mathrm{mV}$ ). These differences were discussed in greater detail in previous work [5].

Interconnection of emulsion silica (Fig. 6b) with magnesium lignosulfonate produced a material with variant properties differing from the initial materials $[35,36]$. Over the whole of the studied $\mathrm{pH}$ range, the electrokinetic potential of the hybrid materials takes negative values (isoelectric points do not occur), and decreases even more with an increase in the alkalinity of the environment. A similar relationship was observed for hybrid materials based on Stöber silica (Fig. 6a). The examined dispersive systems of all of the products are stable in weak acidic, neutral and basic conditions. Lower values of zeta potential, which might indicate coagulation of the systems, were recorded only in strong acidic conditions (the values of the electrokinetic potential of the products 
at the lowest measured point of the $\mathrm{pH}$ scale equal to 1.7, depending on the magnesium lignosulfonate content, ranged from about -10 to $-20 \mathrm{mV}$ ). The shapes of the electrokinetic curves of the hybrid materials are similar, with slight differences connected with the magnesium lignosulfonate content in the final product and the type of silica used.

\subsection{Parameters of porous structure}

Investigation of the porous structure parameters involved determination of the values of BET surface area, total pore volume and mean size of pores. Spherical silicas have low BET surface area, particularly $\mathrm{SiO}_{2}$ obtained via the sol-gel method, for which the BET surface area was found to be $7 \mathrm{~m}^{2} / \mathrm{g}$. The BET surface area of emulsion silica was six times higher than this, although compared with other types of silica (see for review [37, 38]) the value is still not significant. The lowest value of BET surface area, equal to $1 \mathrm{~m}^{2} / \mathrm{g}$, was recorded for magnesium lignosulfonate. Interestingly, during the adsorption of substances on the surface of the hybrid materials it is not BET surface area that is crucial, but the nature and quantity of various functional groups present on the surface of the biopolymer. A very interesting, although expected, observation concerned the change in porous structure parameters depending on the magnesium lignosulfonate content in the materials. The higher the content of lignosulfonate, the lower the BET surface area. Similar behavior was found for the parameters of total pore volume and average size of pores - the differences are shown in Table 4.

Table 4. Porous structure parameters of magnesium lignosulfonate/silica hybrid materials and of the precursors used (MLS and two types of $\mathrm{SiO}_{2}$ ).

\begin{tabular}{ccccc}
\hline $\begin{array}{c}\text { Type } \\
\text { of } \mathrm{SiO}_{2} \\
\text { synthesis }\end{array}$ & $\begin{array}{c}\text { Content of kraft } \\
\text { lignin in relation } \\
\text { to the silica } \\
\text { matrix } \\
\text { (wt./wt. })\end{array}$ & $\begin{array}{c}\text { BET } \\
\text { surface } \\
\text { area } \\
\left(\mathrm{m}^{2} / \mathrm{g}\right)\end{array}$ & $\begin{array}{c}\text { Total } \\
\text { volume } \\
\text { of pores } \\
\left(\mathrm{cm}^{3} / \mathrm{g}\right)\end{array}$ & $\begin{array}{c}\text { Mean size } \\
\text { of pores } \\
(\mathrm{nm})\end{array}$ \\
\hline sol-gel & 3 & 3 & 0.002 & 3.1 \\
method & 20 & 2 & 0.002 & 3.4 \\
\hline non-polar & 50 & 1 & 0.001 & 2.4 \\
media & 3 & 34 & 0.026 & 3.1 \\
\hline
\end{tabular}


Cont. Table 4.

\begin{tabular}{lccc} 
Stöber silica (sol-gel method) & 7 & 0.007 & 2.8 \\
Emulsion silica (non-polar media) & 42 & 0.167 & 3.3 \\
Magnesium lignosulfonate (MLS) & 1 & 0.001 & 11.4 \\
\hline
\end{tabular}

\subsection{Thermal analysis}

Thermal analysis allowed several conclusions to be drawn concerning the pure precursors as well as the final hybrid materials (see Fig. 7).

(a)
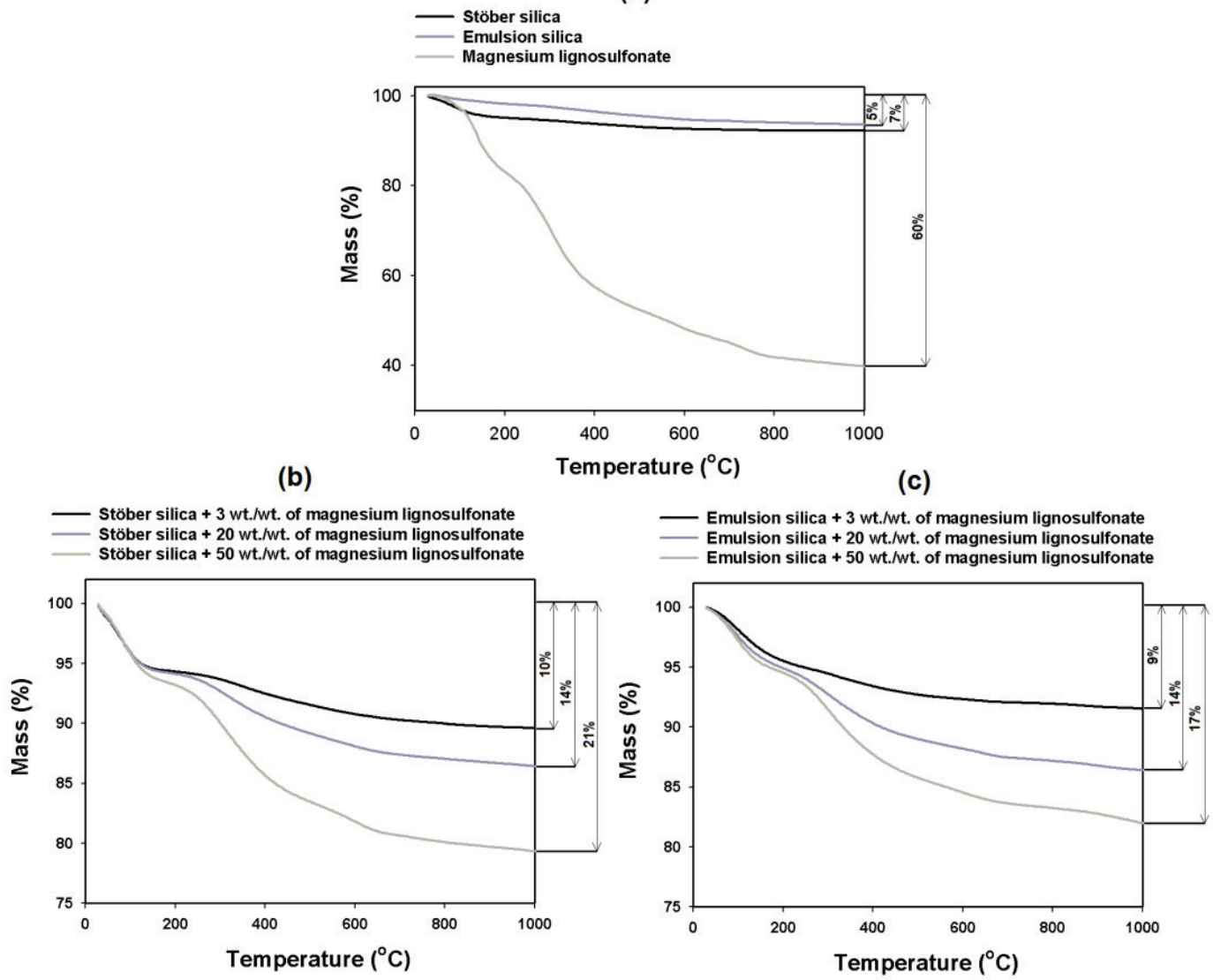

Fig. 7. Thermal analysis of the magnesium lignosulfonate and silicas used (a) and of lignosulfonate/silica hybrid materials based on Stöber silica (b) and emulsion silica (c).

Silica has very high thermal stability, and mass loss during heating is minimal, about $7-8 \%$. The mass loss is connected with the presence of adsorbed water on the surface of the material, as confirmed by the FTIR 
spectra. This observation was also reported in our previous work, in which other types of silica were used [37]. As regards the thermal analysis of magnesium lignosulfonate, the mass loss over the temperature range $25-1000^{\circ} \mathrm{C}$ is significantly higher and reaches $60 \%$. Similar results were observed for kraft lignin, and detailed results appear in [37]. In line with expectations, the resulting lignosulfonate/silica hybrid materials exhibited relatively good thermal stability. It is noteworthy, first, that with an increase in the lignosulfonate content in the hybrid material the thermal stability of the product decreases slightly. Secondly, products based on emulsion silica exhibit slightly better thermal properties than those obtained using sol-gel silica. The good thermal stability of lignosulfonate/silica materials certainly allows them to be applied in various branches of industry, including as a filler in polymer processing.

\subsection{Colorimetric parameters}

Colorimetric analysis supplies basic data regarding the color of the obtained hybrid materials and the precursors used. This is of key significance for future research concerning specific applications of the materials, e.g. as polymer fillers. The measurements showed that the lowest parameter of lightness $\mathrm{L}^{*}$ was that of magnesium lignosulfonate, which also had the highest values of the parameters $\mathrm{a}^{*}=12.16$ (related to red color content) and $\mathrm{b}^{*}=26.92$ (related to yellow color content). Silicas, due to their white color, have high values of the lightness parameter $L^{*}$ : 93.71 and 93.23 for Stöber and emulsion silica respectively. Significant changes were observed in the analysis of colorimetric data and digital photographs (see Fig. 8) of the lignosulfonate/silica hybrid materials, although the changes are more marked for materials containing emulsion silica.

This most likely suggests that the interconnectivity of lignosulfonate with emulsion silica is better than with silica obtained via the sol-gel method. This conclusion is supported by observations already mentioned in the descriptions of the FTIR spectra (see Fig. 5) and elemental analysis (see Table 3). Most importantly in the context of this research, with increasing content of magnesium lignosulfonate the products obtained become more and more brown. This fact has important practical significance for tests of applications of the materials. It may represent something of a limitation, in terms of esthetic considerations, in the case of colorless products or those with low color saturation. 
(a)

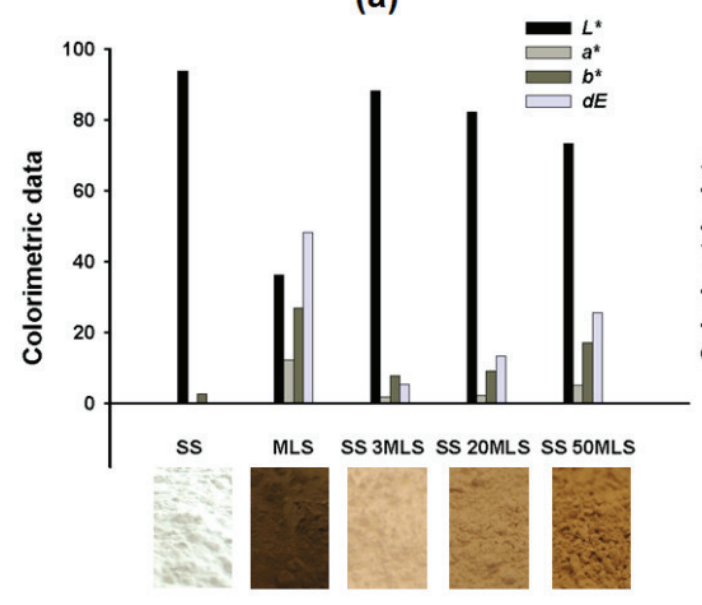

(b)

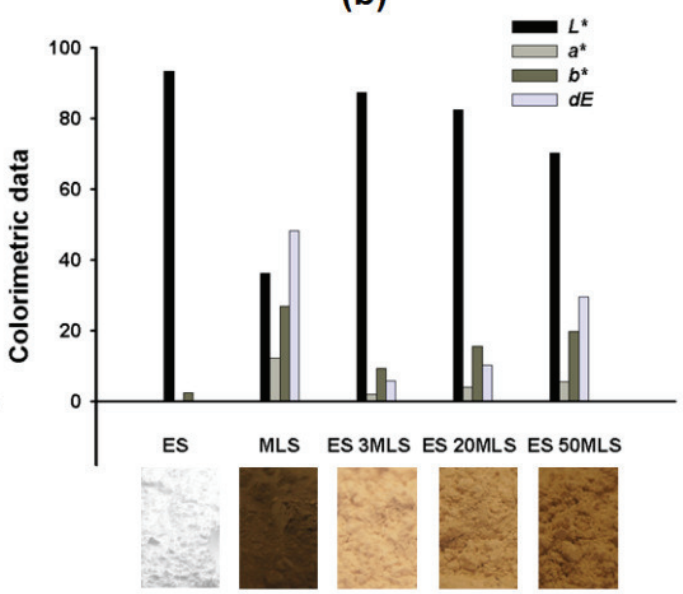

Fig. 8. Colorimetric data and digital photos of precursors and hybrid materials based on Stöber (a) and emulsion (b) silica.

\section{CONCLUSIONS}

Based on inexpensive, renewable magnesium lignosulfonate, generated as a waste product of the sulfonate process of wood dissolution, and silicas synthesized via two different methods, hybrid materials have been obtained.

The dispersive-morphological properties of these materials were determined. The synthesized products possess spherical and regular particles, which with an increase in the lignosulfonate content of the hybrid matrix tend to aggregate and agglomerate.

The effectiveness of interconnection of lignosulfonate with silica was confirmed by FTIR spectroscopy, and indirectly by elemental analysis. The results indicate that hydrogen interactions take place between the precursors.

With a view to establishing their industrial utility, a number of analyses were carried out to determine various parameters of the materials. They were found to have high electrokinetic and thermal stability, as well as defined porous structure and color parameters. All of the data obtained will contribute to the identification of the most suitable applications of the prepared materials in various fields, which will be a topic of future publications. 


\section{ACKNOWLEDGEMENTS}

The study was financed by the National Science Center Poland under decision no. DEC-2013/09/B/ST8/00159.

\section{REFERENCES}

[1] K. Xie, Y. Yu and Y. Shi, Carbohydrate Polym., 78, 799, (2009).

[2] S. Sequeira, D.V. Evtuguin and I. Portugal, Polym. Compos., 30, 1275, (2009).

[3] W. Xiao, J. Xu, X. Liu, Q. Hu and J. Huang, J. Mater. Chem. B, 1, 3477, (2013).

[4] G. Telysheva, T. Dizhbite, L. Jashina, A. Andersone, A. Volperts, J. Ponomarenko and N. Mironova-Ulmane, BioResources, 4, 1276, (2009).

[5] Ł. Klapiszewski, M. Nowacka, G. Milczarek and T. Jesionowski, Carbohydrate Polym., 94, 345, (2013).

[6] T. Jesionowski, Ł. Klapiszewski and G. Milczarek, J. Mater. Sci., 49, 1376, (2014).

[7] R. Núñez-Flores, B. Giménez, F. Fernández-Martín, M.E. LópezCaballero, M.P. Montero and M.C. Gómez-Guillén, Food Hydrocolloids, 27, 60, (2011).

[8] H. Luo, Q. Shen, F. Ye, Y.F. Cheng, M. Mezgebe and R.J. Qin, Mater. Sci. Eng. C, 32, 2001, (2012).

[9] W. Stöber, A. Fink and E. Bohn, J. Colloid Interface Sci., 26, 62, (1968).

[10] I.A.M. Ibrahim, A.A.F. Zikry and M.A. Sharaf, J. Am. Sci., 6, 985, (2010).

[11] Ł. Klapiszewski, M. Królak and T. Jesionowski, Cent. Eur. Journal of Chemistry, 12, 173, (2014).

[12] J. Żurawska, A. Krysztafkiewicz and T. Jesionowski, Surf. Interface Anal., 35, 914, (2003).

[13] T. Jesionowski, J. Żurawska, A. Krysztafkiewicz, M. Pokora, D. Waszak and W. Tylus, Appl. Surf. Sci., 205, 212, (2002).

[14] T. Jesionowski, Powder Technol., 127, 56, (2002).

[15] T. Jesionowski, J. Mater. Sci., 37, 5275, (2002).

[16] G. Wypych, Handbook of Fillers, Chemical Technology Publishing, 2010. 
[17] M. Fišerová, E. Opálená and M. Maholányiová, Cellulose Chem. Technol., 47, 583, (2013).

[18] M.J. Feria, J.C. Garcia, M.A.M. Zamudio, J.L. Gomide, J.L. Colodette and F. López, Cellulose Chem. Technol., 47, 595, (2013).

[19] K. Chakrabarty, K.V. Krishna, P. Saha and A.K. Ghoshal, J. Membrane Sci., 330, 135, (2009).

[20] W.O.S. Doherty, P. Mousavioun and C.M. Fellows, Ind. Crop. Prod., 33, 259, (2011).

[21] G. Lota and G. Milczarek, Electrochem. Commun., 13, 470, (2011).

[22] N.E.El Mansouri and J. Salvad'o, Ind. Crop. Prod., 24, 8, (2006).

[23] M.Y.A. Mollah, P. Palta, T.R. Hess, R.K. Vempati and D.L. Cocke, Cement Concrete Res., 25, 671, (1995).

[24] S.A. Gundersen, Ø. Sæther and J. Sjoblom, Colloid Surface A, 186, 141, (2001).

[25] E.A. Borges da Silva, M. Zabkova, J.D. Araújo, C.A. Cateto, M.F. Barreiro, M.N. Belgacem, and A.E. Rodrigues, Chem. Eng. Res. Des., 87, 1276, (2009).

[26] J. Roszyk, O. Nowosielski and W. Breś, Acta Agrophys., 7, 991, (2006).

[27] Ł. Klapiszewski, M. Mądrawska and T. Jesionowski, Physicochem. Probl. Miner. Process., 48, 463, (2012).

[28] D. Yea, M. Zhanga, L. Gana, Q. Lia and X. Zhanga, Int. J. Biol. Macromol., 60, 77, (2013).

[29] D. Yea, X. Jianga, C. Xiaa, L. Liua and X. Zhanga, Carbohydrate Polym., 89, 876, (2012).

[30] D. Wanga, Y. Linc and W. Dua, Int. Biodeter. Biodegr., 85, 365, (2013).

[31] K. Szwarc-Rzepka, B. Marciniec and T. Jesionowski, Adsorption, 19, 483, (2013).

[32] H. Liu, S. Fu, H. Li and H. Zhan, Ind. Crop. Prod., 30, 287, (2009).

[33] D. Yang, X. Qiu, Y. Pang and M. Zhou, J. Dispersion Sci. Technol., 29, 1296, (2008).

[34] X. Ouyang, L. Ke, X. Qiu, Y. Gu and Y. Pang, J. Dispersion Sci. Technol., 30, 1, (2009).

[35] Y. Ge, Z. Li, Y. Pang and X. Qiu, Int. J. Biol. Macromol., 52, 300, (2013).

[36] D. Yang, X. Qiu, M. Zhou and H. Lou, Energy Convers. Manage., 48, 2433, (2007). 
[37] Ł. Klapiszewski, M. Nowacka, K. Szwarc-Rzepka and T. Jesionowski, Physicochem. Probl. Miner. Process., 49, 497, (2013).

[38] M. Nowacka, Ł. Klapiszewski, M. Norman and T. Jesionowski, Cent. Eur. J. Chem., 11, 1860, (2013).

\section{CURRICULA VITAE}

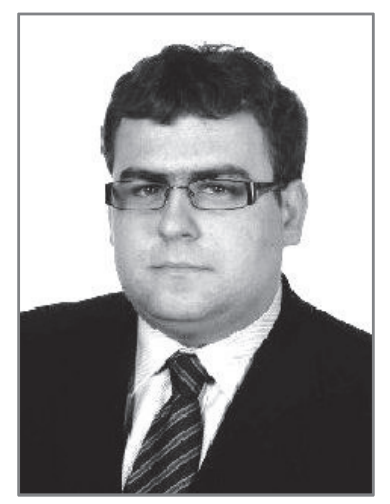

\section{Lukasz Klapiszewski, Ph.D., Eng.}

Institute of Chemical Technology and Engineering,

Faculty of Chemical Technology,

Poznan University of Technology,

Poznan, Pl-60965, Poland

e-mail: lukasz.klapiszewski@put.poznan.pl

Lukasz Klapiszewski graduated from the Faculty of Chemical Technology, Poznan University of Technology (PUT), receiving the degree of Master and Engineer of Chemistry. He defended his doctoral thesis in the Institute of Chemical Technology and Engineering, PUT in 2014. He has been employed in the Institute of Chemical Technology and Engineering, Faculty of Chemical Technology. Now he is an assistant of the Division of Chemical Technology.

He have published over 25 publications ranked by Thomson Reuters Journal Citation Reports, and additionally is holding 6 patents and patents applications.

His research and scientific areas are: inorganic-organic hybrid materials, surface and colloids science, polymer processing, environmental pollution protection.

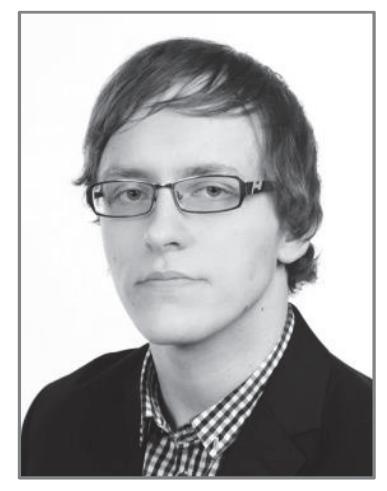

Tadeusz Jan Szalaty, Eng.

Institute of Chemical Technology and Engineering,

Faculty of Chemical Technology,

Poznan University of Technology,

Poznan, Pl-60965, Poland

e-mail: tadeuszszalaty91@gmail.com

Tadeusz Jan Szalaty graduated from the Faculty of Chemical Technology, Poznan University of Technology (PUT), receiving the degree of Engineer of Chemistry. 
Now he is PhD student at the Faculty of Chemical Technology PUT.

His research and scientific areas are: hybrid materials and biomaterials preparation and characterization, ionic liquids, surface and colloids science.

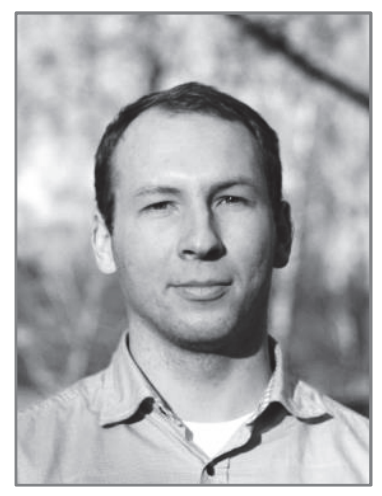

Tomasz Szatkowski, M.Sc., Eng.

Institute of Chemical Technology and Engineering,

Faculty of Chemical Technology,

Poznan University of Technology,

Poznan, Pl-60965, Poland

e-mail: tomasz.p.szatkowski@doctorate.put.poznan.pl

Tomasz Szatkowski graduated from the Faculty of Chemical Technology at Composite and Nanomaterials speciality, Poznan University of Technology (PUT), receiving the degree of Master and Engineer of Chemistry in 2012. At the same year he enrolled to a PhD course under scientific supervision of Professor Teofil Jesionowski. In 2013 he have begun a cooperation with Professor Hermann Ehrlich of TU Bergakademie Freiberg which is being continued till present.

So far, he took part in 2 internships $(3$ months in Universita degli di Trieste, Italy; and 6 months in TU Bergakademie Freiberg, Germany).

His research and scientific areas are: nanomaterials, composites, biomineralization and bimimetic materials, hydrothermal reactions.

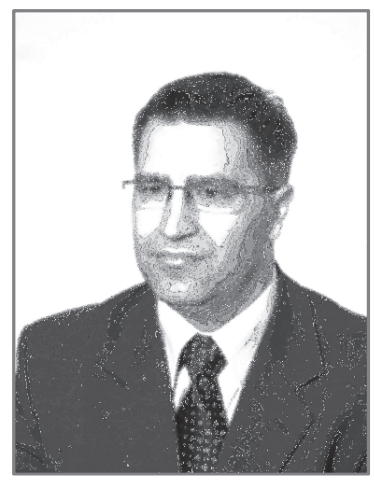

Professor Teofil Jesionowski, Ph.D., D.Sc., Eng. Institute of Chemical Technology and Engineering, Faculty of Chemical Technology, Poznan University of Technology, Poznan, Pl-60965, Poland e-mail: Teofil.Jesionowski@put.poznan.pl

Teofil Jesionowski graduated from the Faculty of Chemical Technology, Poznan University of Technology (PUT), receiving the degree of Master and Engineer of Chemistry. He defended his doctoral thesis in the Institute of Chemical Technology and Engineering, PUT in 1999. He has been employed in the Institute of Chemical Technology and Engineering, Faculty of Chemical Technology. Now he is a professor and head of the Division of Chemical Technology.

He is a member of the editorial board of Dyes and Pigments, Chemical Transactions journals as well as the editor of Physicochemical Problems of Mineral Processing. He have published over 220 publications ranked by 
Thomson Reuters - Journal Citation Reports, 2 book chapters, and additionally is holding 25 patents and patent applications.

His research and scientific areas are: surface and colloids science, dyes and pigments, biomineralization and bimimetic materials, hybrid materials, functional fillers, polymer processing, nanocomposites, environmental pollution protection. 